\title{
LAB MANUAL FOR \\ Metrology and Machine TOOLS
}

\author{
P Gnana Prakesh, B.Tech(M.Tech) \\ ACS Reddy, Ph.D
}




\title{
LAB MANUAL \\ FOR \\ METROLOGY \\ AND \\ MACHINE TOOLS
}

\author{
III B.Tech I SEMESTER \\ MECHANICAL ENGINEERING
}

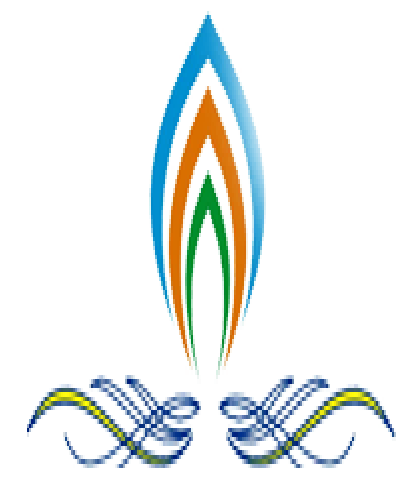

\section{SREYAS INSTITUTE OF ENGINEERING AND TECHNOLOGY}

(affiliated with Jawaharlal Nehru Technological University, Hyderabad)

NAGOLE, HYDERABAD TELANGANA 


\title{
LAB MANUAL FOR \\ METROLOGY AND MACHINE TOOLS
}

\author{
III B.Tech I SEMESTER \\ MECHANICAL ENGINEERING
}

DEPARTMENT

$\mathrm{OF}$

\section{MECHANICAL ENGINEERING}

SREYAS INSTITUTE OF ENGINEERING AND TECHNOLOGY

NAGOLE- HYDERABAD

2020 
Prepared by

Corrected by

Inspected by

Approved by 


\section{SCHEME OF UNIVERSITY PRACTICAL EXAMINATION}

Lab is evaluated for 75 marks and the split is as given below.

INTERNAL EVALUATION

Day-to-day performance $=15$ marks

Model Exam

$=10$ marks

Total

25 marks

\section{UNIVERSITY EXAMINATION}

Aim and Procedure $=10$ marks

Tabulation $=10$ marks

Formulae and Calculation $=10$ marks

Graph and Result $=10$ marks

Viva Voce $=10$ marks

Total

50 marks

Note: Staff maintains the assessment Register and the Head of the Department monitors it. 


\section{GENERAL INSTRUCTIONS FOR LABORATORY CLASSES}

1. Enter Lab with CLOSED FOOTWEAR

2. Apron/uniform is a must for attending lab and Boys must TUCK IN the shirts

3. LONG HAIR should be protected, let it not be loose especially near rotating machinery.

4. Any other machines/ equipments should not be operated other than the prescribed one for that day.

5. POWER SUPPLY to your experiment get only through designated LAB TECHNICIAN only.

6. Do not LEAN and do not be CLOSE to the rotating components.

7. All tools must be returned before leaving and the table/ machine must be throughly cleaned.

8. HEADINGS \& DETAILS should be neatly written
(a) Aim of the experiment
(b) Apparatus / Tools/ Instruments required
(c) Procedure / Theory / Algorithm / Program
(d) Model Calculations
(e) Neat Diagram/ Flow charts
(f) Specifications/ Designs details
(g) Tabulation
(h) Graph 
(i) Result/ Discussions

9. Before doing the experiment, the student should get the WORKING PROCEDURE approval from the faculty in-charge

10. Experiment date should be written in the appropriate place

11. After completing the experiments, the answer to the VIVA-VOCE Questions should be neatly written in the workbook

12. Since additional instructions may be given at the beginning of laboratory sessions, it is important that all students arrive at each session on time.

13. Every student should obtain a copy of the laboratory manual.

14. Dress code: Students must come to the laboratory wearing:

(a) trousers

(b) half-sleeve tops and

(c) Leather shoes.

(d) Half pants, loosely hanging garments and slippers are not allowed.

15. To avoid any injury, the student must take the permission of the laboratory staffs before handling the machines.

16. Every student is required is STUDENT IS REQUIRED TO HANDLE THE EQUIPMENT WITH CARE.

17. Students must ensure that their work areas are clean.

18. At the end of each experiment, the student must take initials from the staff on your data/observations.

19. Laboratory report must be submitted in standard sheet, available at stores in the subsequent lab turn. Reports on ordinary sheets and computer papers will not be accepted.

20. Each member of any group must submit lab report even if the experiment has been performed in a group.

21. The lab report must contain:

(a) Title of the experiment,

(b) Three to four lines stating the objectives, 
(c) A few lines on background;

(d) Name of all equipments/tools used along with one line description of its use

(e) Neatly labeled sketches.

22. Student can check their laboratory reports after correction for discussion. 


\begin{tabular}{|c|c|c|c|c|c|c|c|c|}
\hline$\underset{\infty}{\infty}$ & & & & & & & & \\
\hline 壳 & & & & & & & & \\
\hline 苞 & & & & & & & & \\
\hline 总 & & & & & & & & \\
\hline$\stackrel{\Xi}{ \pm}$ & & & & & & & & \\
\hline ָึ & & & & & & & & \\
\hline$\stackrel{\widetilde{\Xi}}{\sim}$ & & & & & & & & \\
\hline$\stackrel{ \pm}{ \pm}$ & & & & & & & & \\
\hline$\stackrel{\Xi}{\oplus}$ & & & & & & & & \\
\hline$\stackrel{\widetilde{a}}{\sigma}$ & & & & & & & & \\
\hline$\stackrel{\infty}{\infty}$ & & & & & & & & \\
\hline $\overrightarrow{\mathbb{N}}$ & & & & & & & & \\
\hline$\approx$ & & & & & & & & \\
\hline 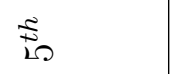 & & & & & & & & \\
\hline $\mathbb{E}_{\forall}$ & & & & & & & & \\
\hline సั & & & & & & & & \\
\hline ゙ָ๊ & & & & & & & & \\
\hline$\vec{\omega}$ & & & & & & & & \\
\hline$\wedge$ & 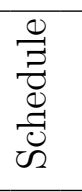 & $\begin{array}{l}\overrightarrow{0} \\
\stackrel{\mathbb{U}}{1}\end{array}$ & 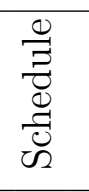 & 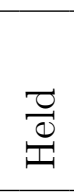 & $\begin{array}{l}\frac{0}{J} \\
\underset{D}{0} \\
\frac{d}{0} \\
\text { U }\end{array}$ & 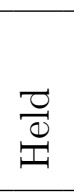 & $\begin{array}{l}0 \\
\\
\\
0 \\
\frac{0}{0} \\
\text { Un }\end{array}$ & 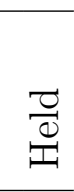 \\
\hline 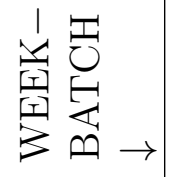 & $\varangle$ & & 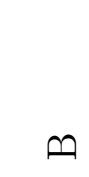 & & $\circlearrowright$ & & 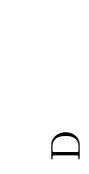 & \\
\hline
\end{tabular}

MECH DEPT ii

$\mathrm{M}$ and M T Lab manual 


\section{REPORT FORMAT}

The report must be hand written. A report should include the following in order

1. A title page, which includes the following information, in order:

(a) Course Number and Section Number

(b) Experiment Title

(c) Names of the Group Members (who contributed to do the lab/report)

(d) Due Date

2. Objective or purpose of the experiment work.

3. Theoretical aspect of the experiment.

4. Experimental procedure that explains briefly the procedure of how the experiment was performed and all the equipment used.

5. Experimental and/or calculated results. (Include all data you have taken, a sample calculation, and the results) The result table must be presented in tabular form. Also, all calculations and graphical work (e.g. graph) must be hand written/drawn.

6. Discussion of results in light of the theoretical predictions. Include an error analysis. Quantify the errors whenever possible.

7. Conclusions, wherein you write what you learned from the experiment. Your conclusions must summarize your report and must be based on your experimental results

Lab reports are due at the beginning of next lab. Late lab reports will not be accepted. Note: In order to get a good grade in the lab, please follow the instructions listed below: 
1. Read about the lab prior to the beginning of the lab. Do each lab with an attitude of learning.

2. Please bring your lab manual to the lab. Each group should have at least one lab manual with them.

3. Students are advised to bring blank and graph papers to the lab, on which you can do calculations and draw graphs. 


\section{GENERAL INSTRUCTIONS}

1. Since additional instructions may be given at the beginning of laboratory sessions, it is important that all students arrive at each session on time.

2. Every student should obtain a copy of the laboratory manual.

3. Dress code: Students must come to the laboratory wearing:

(a) trousers

(b) half-sleeve tops and

(c) Leather shoes.

(d) Half pants, loosely hanging garments and slippers are not allowed.

4. To avoid any injury, the student must take the permission of the laboratory staffs before handling the machines.

5. Every student is required is STUDENT IS REQUIRED TO HANDLE THE EQUIPMENT WITH CARE.

6. Students must ensure that their work areas are clean.

7. At the end of each experiment, the student must take initials from the staff on your data/observations.

8. Laboratory report must be submitted in standard sheet, available at stores in the subsequent lab turn. Reports on ordinary sheets and computer papers will not be accepted.

9. Each member of any group must submit lab report even if the experiment has been performed in a group.

10. The lab report must contain:

(a) Title of the experiment,

(b) Three to four lines stating the objectives, 
(c) A few lines on background;

(d) Name of all equipments/tools used along with one line description of its use

(e) Neatly labeled sketches.

11. Student can check their laboratory reports after correction for discussion. 


\section{SAFETY PRECAUTIONS}

1. Follow all safety instructions given in the class and in the laboratories.

2. All students must read and understand the information in this document with regard to laboratory safety and emergency procedures prior to the first laboratory session.

3. Be careful in touching and handling specimens in hot working operations like casting, arc welding and spotwelding. Use tongs or glouses where ever it requires.

4. Students must adhere to written and verbal safety instructions throughout the academic term.

5. It is your responsibility to read safety and fire alarm posters and follow the instructions during an emergency

6. Know the location of the fire extinguisher, eye wash, and safety shower in your lab and know how to use them.

7. Notify your instructor immediately after any injury, fire or explosion, or spill.

8. Know the building evacuation procedures.

9. Good common sense is needed for safety in a laboratory. It is expected that each student will work in a responsible manner and exercise good judgment and common sense.

10. It is always better to ask questions than to risk harm to yourself or damage to the equipment.

11. Never eat, drink, or smoke while working in the laboratory.

12. Read labels carefully.

13. Do not use any equipment unless you are trained and approved as a user by your supervisor. 
14. Wear safety glasses or face shields when working with hazardous materials and/or equipment.

15. Wear gloves when using any hazardous or toxic agent.

16. Clothing: When handling dangerous substances, wear gloves, laboratory coats, and safety shield or glasses.

17. Shorts and sandals should not be worn in the lab at any time.

18. Shoes are must while working in the machine shops.

19. If you have long hair or loose clothes, make sure it is tied back or confined.

20. Keep the work area clear of all materials except those needed for your work.

21. Disposal - Students are responsible for the proper disposal of used material if any in appropriate containers.

22. Equipment Failure - If a piece of equipment fails while being used, report it immediately to your lab assistant or tutor. Never try to fix the problem yourself because you could harm yourself and others.

23. If leaving a lab unattended, turn off all ignition sources and lock the doors.

24. Clean up your work area before leaving.

25. Wash hands before leaving the lab and before eating.

26. Obtain permission before operating any high voltage equipment.

27. Maintain an unobstructed access to all electrical panels.

28. When using compressed air, use only approved nozzles and never direct the air towards any person.

29. Guards on machinery must be in place during operation.

30. Exercise care when working with or near hydraulically- or pneumaticallydriven equipment. Sudden or unexpected motion can inflict serious injury.

31. Dispose of waste and broken glassware in proper containers.

32. If you suspect that you have suffered an eye injury, notify your instructor or teaching assistant IMMEDIATELY! Your ability to recover from an eye injury decreases the longer you wait for treatment. 
33. Never do unauthorized experiments.

34. Never work alone in laboratory.

35. Keep your lab space clean and organized.

36. Do not leave an on-going experiment unattended.

37. Maintain unobstructed access to all exits, fire extinguishers, electrical panels, emergency showers, and eye washes.

38. Be careful when lifting heavy objects

39. Clean your lab bench and equipment before you leave the laboratory. 


\section{PREFACE}

- In this course we are seeking to understand different production processes through laboratory experiments.

- The students must have a fairly good understanding of the theory underlying the experiments.

- The entire course is designed such that classroom lectures precede lab work.

- Students are advised to pay close attention in class so that they can perform well in the lab.

- Usually the class is divided into groups.

- Each group will do a different experiment every week until all the required experiments are completed.

- Students will be formed into groups of three or four on the first lab day. Once a student has signed up with a group, he or she may not change groups without prior approval of the instructor.

- You will perform the experiment in group, and turn in ONE REPORT PER GROUP. Your report should be self-contained, i.e. an engineering technologist should be able to perform the experiment and duplicate your results by reading your report.

- DO NOT "adjust" your data to make them fit what you believe to be an acceptable value. Your report should be an accurate description of the experiment.

- If your results differ significantly from reference values you should check your settings carefully (calibration, wrong units, wrong calculations, etc.), and do the experiment again.

- Try to explain any discrepancies but do not "adjust" your data. 
- It is important that all the information necessary to complete the lab report is obtained before students leave the lab. 


\title{
JNTUH PRESCRIBED SYLLABUS
}

\section{JAWAHARLAL NEHRU TECHNOLOGICAL UNIVERSITY HYDERABAD}

\author{
II Year B.Tech .ME-II Sem \\ $\mathrm{L} / \mathrm{T} / \mathrm{P} / \mathrm{D} \quad \mathrm{C}$ \\ $-\quad / 3 /-2$
}

(A50384) METROLOGY AND MACHINE TOOLS LAB

Section - A:

1. Use of gear teeth vernier calipers for checking the chordal addedndum and chordal height of the spur gear.

2. Machine tool alignment of test on the lathe.

3. Tool makers microscope and its application Angle and taper measurements by bevel protractor and sine bars.

4. Use of spirit level and optical flats in finding the flatness of surface plate.

5. Thread measurement by 2 -wire and 3 -wire methods.

Section - B:

1. Introduction of general purpose machine - Lathe,

2. Drilling machine, Milling machine, Shaper.

3. Planing machine, slotting machine, Cylindrical 
4. Grinder, surface grinder and tool and cutter grinder.

5. Step turning and taper turning on lathe machine.

6. Thread cutting and knurling on -lathe machine.

7. Drilling and Taping

8. Shapping and Planning

9. Slotting

10. Milling

11. Cylindrical Surface Grinding

12. Grinding of Tool angles.

$\mathrm{L} \rightarrow$ Lecture, $\mathrm{T} \rightarrow$ Theory, $\mathrm{P} \rightarrow$ Practical, $\mathrm{C} \rightarrow$ Credits 


\section{Contents}

1 Use OF Gear Teeth Vernier Calipers for Checking the Chordal Addendum

2 Machine tool alignment of test on the lathe 5

3 Tool makers microscope and its application 6

4 Angle and Taper Measurement by Bevel Protractor and Sine bar 12

5 Use of spirit level and optical flats in finding the flatness of surface $\begin{array}{lr}\text { plate } & \mathbf{1 5}\end{array}$

6 Thread measurement by 2-wire and 3-wire methods 16

7 Introduction to General Purpose Machine Tools- Lathe, Drilling, $\begin{array}{ll}\text { milling and shaper machines } & 17\end{array}$

8 Step Turning and Taper Turning on Lathe Machine 21

9 Thread Cutting and knurling on lathe machine 25

10 Drilling and Taping Operations $\quad 29$

11 Shaping and Planning 33

12 Slotting $\quad 34$

13 Milling $\quad 35$

14 Cylindrical Surface Grinding $\quad 36$

$\begin{array}{ll}15 \text { Grinding of tool angles } & 37\end{array}$ 


\section{EXPERIMENTS AS PER SYLLABUS}




\section{Experiment 1}

\section{Use OF Gear Teeth Vernier Calipers for Checking the Chordal Addendum}

\subsection{Aim}

To measure various parameters of gear tooth

\subsection{Introduction}

\subsection{Terminology of gear tooth}

Pitch circle diameter PCD

: It is the diameter of a circle by pure rolling action would produce the same motion as the tooged gear wheel

\section{Module}

It is defined as the length of the pitch circle diameter per tooth. Thus if PCD of gear be $\mathrm{D}$ and number of teeth $\mathrm{N}$, then module $\mathrm{m}$ is $\mathrm{D} / \mathrm{N}$. It is generally expressed in $\mathrm{mm}$.

\section{Diametral pitch}

: It is expressed as the number of teeth per inch of the PCD 


\section{Circular pitch}

It is the arc distance measured around the pitch circle from the flank of one tooth to a similar flank in the next tooth. C.P $=\pi \mathrm{D} / \mathrm{N}=\pi \mathrm{m}$

\section{Addendum}

: This is the radial distance from the pitch circle to the tip of the tooth. Its value is equal to one module.

\section{Clearance}

: This is the radial distance from the tip of a tooth to the bottom of a mating tooth space when the teeth are symmetrically engaged. Its standard value is 0.157 times module.

\section{Dedundum}

This is the radial distance from the pitch circle to the bottom of the tooth space. Dedundum $=$ Addendum + clearance $=\mathrm{m}+0.157 \mathrm{~m}=1.157 \mathrm{~m}$

\section{Blank diameter}

This is the arc distance measured along the pitch circle from which the gear is cut. It is equal to PCD plus twice the addendum.

Blank diameter $=\mathrm{PCD}+2 \mathrm{~m}=\mathrm{m} \mathrm{N}+2 \mathrm{~m}=\mathrm{m}(\mathrm{N}+2)$

\section{Tooth thickness}

This is the arc distance measured along the pitch circle from its intercept with on flank to its intercept with the other flank of the same tooth.

Normally tooth thickness $=\frac{1}{2}(C . P)=\frac{1}{2}(\pi \cdot m)$

But thickness is usually reduced by certain amount to allow for some amount of backless and also owing to addendum correction.

\section{Face of tooth}

It is that part of the tooth surface which is above the pitch surface.

\section{Flank of tooth}

It is that part of the tooth surface which is below the pitch surface. 


\subsection{Measurement off Tooth thickness}

The permissible error or tolerance in thickness of tooth is the variation of actual thickness of tooth from its theoretical value. The tooth thickness is generally measured at pitch circle and is therefore the pitch line thickness of tooth i.e. the length of an arc, which is difficult to measure directly. In most of the cases it is sufficient to measure the chordal thickness, the difference between chordal tooth thickness and circular tooth thickness is very small pitch. The thickness measurement is the most important measure because most of the gears manufactures may not undergo checking for all other parameters, but thickness measurement is a must for all gears.

The tooth thickness can be measured by gear tooth vernier. The gear tooth thickness from the tio to the base circle of the tooth the instrument must be capable of measuring the tooth thickness of a specified position of the tooth. Further this is possible only when there is some arrangement to fix that position where the measurement has to be taken. The gear tooth vernier has a vernier scales and they are set for width $(\mathrm{w})$ of the tooth and depth (d) from the top at which w occurs.

\subsection{Procedure}

1. Count the no of teeth

2. Measure the outside diameter of gear

3. Calculate the chordal addendum

4. Set the gear tooth vernier calipers for depth $\mathrm{d}, \mathrm{w}$

5. Repeat the measurement on other teeth. Find average value

\subsection{Calculations}

$$
\begin{gathered}
\text { Chordaladdendum }(d)=\frac{N x M}{2}\left[1+\frac{2}{N}-\cos \frac{90}{N}\right. \\
\text { Chordalthickness }(w)=N \cdot M \cdot \sin (90 / N)
\end{gathered}
$$

\subsection{Precautions}

1. Dont press the jaws too height 
2. See the reading without parallax error.

3. Ideal condition The instrument should be error free.

4. Repeatability is required

\subsection{Result}

1.9 Safety Precautions

1.10 VIVA 


\title{
Experiment 2
}

Machine tool alignment of test on the lathe

\author{
2.1 Introduction
}

alignment 


\section{Experiment 3}

\section{Tool makers microscope and its application}

\section{$3.1 \quad$ AIM}

To measure the pitch and angle of the screw thread. sectionPPARATUS Tool makers

1. Tool makers microscope

2. screw thread specimen

\subsection{THEORY}

Tool makers microscope is based on the Principle of optics. The microscope consists of a heavy-duty hallow-duty hallow base, which accommodates the illuminating unit underneath, and above this on the top surface of the base, the work table carriage is supported on ball and controlled by micrometer screws. Projecting up from the rear of the base is a column, which carries the microscope unit and various interchangeable eyepieces.

The chief applications of the tool room microscope are as follows

1. The determination of relative position of various points on work.

2. Measurement of angle by using a protractor eyepiece.

3. Comparison of thread forms with master profiles engraved in the eyepiece, measurement of pitch and effective diameter. 


\subsection{SPECIFICATIONS}

MAGNIFICATION : 30X (Standard)

OBJECTIVE : $2 \mathrm{X}$

EYEPIECE : W.F.15X with cross rectile

FIELD OF VIEW : 8mm. (approx)

WORKING DISTANCE : $80 \mathrm{~mm}$

OBSERVATION TUBE : monocular inclined at 30 degree

STAND : large and heavy base provide extra overall rigidity to the instrument MEASUREMENT STAGE : 150X150. Size travel up to 50mm in each direction, least count 6 minutes.

\subsection{CONSTRUCITON OF MICROSCOPE}

\section{BASE}

The study base rest on three support two of which are adjustable for leveling the instrument. The base has built in all electrical transformers and their control panel and transmitted illuminator with green filter.

\section{ARM}

The arm has a groove guide on which the microscope tube is vertically adjusted by rack and pinion system.

\section{FOCUSSING MECHANISM}

The course focusing movement provided in the microscope tube separately. The coarse motion is knurled knob on both side of the tube and ha as the total travel of $200 \mathrm{~mm}$. Its also lock any position by lever, this movement is characterized by its exceptionally smooth and accurate precision. The vertical travel or measurement up to $10 \mathrm{~mm}$, thickness can be read by the depth dial gauge. The thickness is being measured with the difference of two different focusing of object. The least count of gauge is 0.01 .

\section{EYEPIECE PROTRACTOR}

This unique protractor head graduated 0 to 360 degree with adjustable vernier reading to 6 minutes cross line incorporated in the protractor head rotating in the optical axis of the microscope the cross line graticule is replaceable with many other measuring graticules. 


\section{MEASURING STAGE}

The stage plate is of $150 \mathrm{X} 150 \mathrm{~mm}$ having very smooth and precise movements in both axis with special ball racers arrangements. The travel of the stage is $25 \mathrm{~mm}$. in both direction with precise imported micrometer head, least count 0.01 or $0.005 \mathrm{~mm}$. The stage has two T-slots for mounting accessories like rotary stage, center holding device attachment and V-block etc. ROTARY STAGE A rotating stage is fixed in T-slots of square plate having 360 degree graduations on its periphery with vernier reading to6 minute, and lock screw. All types of horizontal angular measurements can be done with this stage.

\section{ILLUMINATING SYSTEM}

Two possible range of illuminating system are provided with standard equipment to meet every application, operated through 6 volts solid state variable light control built in transformer.

1. Sub-stage transmitted light from a bottom source providing collimated green filter halogen light for viewing contours and transparent objects.

2. Surface incident illuminator for shadow free lighting, for high power examination of opaque objects.

\subsection{PROCEDURE}

\section{MEASUREMENT OF SCREW THREAD PITCH}

1. The image of the thread profile is set so that some of the profile coincides with the cross hair as seen on the ground-glass screen.

2. The reading on thimble of the longitudinal micrometer screw is noted down.

3. Then the part is traversed by the micrometer screw until a corresponding point on the profile of the next thread coincides with the cross hairs.

4. The reading on thimble is again noted and the difference in two readings gives the actual pitch of the screw.

\section{MEASUREMENT OF ANGLE OF THREAD}

1. It is determined by rotating the screen until a line on the screen coincides with one flank of the thread profile item The angle of screen rotation is noted and then the screen is further rotated till the same line coincides with the 
other flank of thread. The difference in two angular readings gives the actual angel of thread on the screw.

Table 3.1: TABULAR FORM FOR PITCH OF THE THREAD

\begin{tabular}{|c|c|c|c|}
\hline S.No. & $\begin{array}{c}\text { Initial micrometer } \\
\text { readings on thread pitch A }(\mathrm{mm}) \\
\text { pitch A }(\mathrm{mm})\end{array}$ & $\begin{array}{c}\text { Final micrometer } \\
\text { readings on thread } \\
\text { pitch B }(\mathrm{mm})\end{array}$ & $\begin{array}{c}\text { Pitch of the } \\
\text { thread B-A }(\mathrm{mm})\end{array}$ \\
\hline 1 & & & \\
\hline 2 & & & \\
\hline 3 & & & \\
\hline 4 & & & \\
\hline 5 & & & \\
\hline
\end{tabular}

\subsection{PRECAUTIONS}

1. The coincidence on the component \& cross hairs must be carefully matched.

2. Eyepieces are to be handled carefully.

3. Dont expose eyes directly to the light source.

\subsection{RESULT}

The pitch and flank angle of the given object is measured with toolmakers microscope are tabulated. 
Table 3.2: TABLARFORM FOR FLANK ANGLE OF THE THREAD

\begin{tabular}{|c|c|c|c|}
\hline S.No. & $\begin{array}{c}\text { Initial micrometer } \\
\text { readings on thread pitch A }(\mathrm{mm}) \\
\text { pitch A }(\mathrm{mm})\end{array}$ & $\begin{array}{c}\text { Final micrometer } \\
\text { readings on thread } \\
\text { pitch B }(\mathrm{mm})\end{array}$ & $\begin{array}{c}\text { Pitch of the } \\
\text { thread B-A }(\mathrm{mm})\end{array}$ \\
\hline 1 & & & \\
\hline 2 & & & \\
\hline 3 & & & \\
\hline 4 & & & \\
\hline 5 & & & \\
\hline
\end{tabular}

\subsection{VIVA}

1. What is the use of angle plates?

2. Name some angle measuring devices?

3. What is the least count of mechanical Bevel Protractor?

4. What is the least count of optical Bevel Protractor?

5. What is a sine bar?

6. What are the limitations of Sine bar?

7. What is the difference between the sine bar and sine center?

8. What is the use of V-block?

9. What is the purpose of adjusting nuts in a micrometer?

10. What is the least count of dial indicator? 
11. How do you specify sine bar?

12. How to maintain constant pressure in micrometer?

13. What are the applications of Gear toothvernier caliper?

14. How do we check the profile of a Gear tooth?

15. Name some angle measuring devices?

16. Why do we use Feeler gauges?

17. What are slip gauges and why do we use them?

18. What are slip gauges and why do we use them?

19. Explain zero error and zero correction in case of micrometers?

20. What is the principle involved in sprit levels?

21. What is the least count of digitsl vernier caliper?

22. What is the difference between vernier height gauge, vernier depth gauge, and vernier caliper?

23. Explain briefly about the different types of micrometers?

24. What is the least count of a micrometer and how is it determind?

25. What is the range of dial bore gauge?

26. Define the following terms a) Roughness b) Waviness c) Lay d) Sampling Length

\subsection{Further readings}

https://www.overleaf.com /4205644gzzwsf \#/12417341/ 


\section{Experiment 4}

\section{Angle and Taper Measurement by Bevel Protractor and Sine bar}

\subsection{Aim}

e the angle between two faces of a given component using Bevel Protractor and Sine bar

\subsection{Equipment and accessories required}

1. Bevel Protractor with acute angle attachment( 150/300 length blades) item Sine bar

2. surface plate

3. Bolts for locking sine bar to angle plate

4. clamps for locking component to sine bar

\subsection{Theory}

\section{Bevel protractor}

The bevel protractor is the simplest instrument for measurement of angle between two faces of component. It consists of a base plate attached to the main body and an adjustable blade which is attached to a circular plate called turret containing vernier scale. The adjustable blade is capable of rotating freely about the center of the main scale engraved the body of the instrument and can be locked at any position. An acute angle attachment is provided at the top as shown to measure 
acute angles. The base of the plate is made flat so that it could be laid flat to measure acute angles. The base of the base plate is made flat so that it could be laid flat upon the work and any type of angle measured. It is capable of measuring from zero degrees to 360 degrees.

The vernier scale has 24 divisions coinciding with 46 main scale divisions as shown in Figure. The vernier scale is graduated to the right and left of zero up to 60 minutes each of 12 graduation representing 5 minutes. Since both the protractor dial and vernier scale coincides with protractor graduation on the number of vernier graduations multiplied by 5 minutes must be added to the number of degrees read between the zeros on the protractor dial and vernier scale.

\section{Sine bar}

Sine bar in conjunction with slip gauges constitute a very good device for the precise measurement of angles. The arrangement is based on the fact that for any particular angle $\alpha$ the sides of a right angled triangle will have precise ratio. i.e.,

$$
\sin \theta=\frac{\text { oppositeside }}{\text { Hypotenuse }}=\text { frachl }
$$

If $\mathrm{h}$ and $\mathrm{l}$ could be measured accurately, $\theta$ can be obtained accurately. The value $h$ is built up by slip gauges and the value $l$ is constant for a given side bar. Sine bars are used either for measuring angles very accurately on for locating any work to a given angle with in a very close limit. For precision work, the upper face of the sine bar must be parallel with the plane passing through the axes of both cylinders. The top and bottom faces of the sine bar also must be parallel.

\subsection{Procedure}

\section{procedure for bevel protractor}

1. The base plane of the bevel protractor is placed on the top horizontal surface of the component.

2. Blade locking nut is loosened by a rotating the blade about the center of the main scale, the working edge of the blade is made to coincide with the inclined surface of components.

3. Blade is locked in that position by tightening the nut.

4. Vernier of the surface w.r.t horizontal is calculated as follows.

Angularreading $=$ Vernierscaledivisionx5minutes $)+$ Mainscaledivisionindegrees) 


\section{procedure for sine bar}

1. The sine bar is made to rest on surface plate with rollers connecting the datum

2. Place the component on sine bar and lock it in position

3. Lift one end of the sine bar and place a pack of slip gauges, underneath the roller. The height of slip gauges(h) should be selected such that the top surface of component is parallel to datum plate. If both the surfaces are perfectly parallel, the pointer on the dial gauge shows the same reading throughout the travel of dial gauge stylus. If surfaces are not parallel, then the height of the slip gauge pack(h) can be altered and procedure for checking parallelism can be repeated.

$$
\theta=\sin ^{-1} \frac{h}{l}
$$

\subsection{Tabular form}

Bevel protractor

Sine bar

\subsection{Precautions}

1. The sine bar should not be used for angle greater than 60 degrees because any possible error in construction is accentuated at this limit

2. Accuracy of sine bar should be ensured

3. As far as possible longer sine bar should be used. Since many errors are reduced by using longer bars. 


\section{Experiment 5}

\section{Use of spirit level and optical flats in finding the flatness of surface plate}

\section{$5.1 \quad$ AIM}

To find the flatness of a given surface plate by spirit level and optical flats

\subsection{Apparatus required}

1. spirit level

2. Optical flats

3. surface plate

\subsection{Theory}

The simplest form of flatness testing is possible by comparing the surface with an accurate surface.

Spirit level is used in special cases and called clinoometers, precision micro-optic clinometer utilizes bubble unit wih a iwal metersl $\mathrm{m}$ 


\section{Experiment 6}

\section{Thread measurement by 2-wire and 3-wire methods}




\section{Experiment 7}

\section{Introduction to General Purpose Machine Tools- Lathe, Drilling, milling and shaper machines}

\subsection{AIM}

Introduction to general purpose machines

\subsection{Introduction}

Various machining purpose used these all type of mechanical machining machines are Lathe machine, Shaper machine, Slotting machine, Planning machine, Drilling machine, Boring machine, Milling machine, Grinding machine, Lapping machine Honing machine and Broaching machine

These machines are to producing various operations like namely Facing, Chamfering, Step turning, Taper turning, Plain turning, Knurling, Grooving, Thread cutting, Drilling, Tapping, Precision grinding, Cylindrical grinding, Surface grinding, grinding of tool angles e.t.c.

\section{LATHE MACHINE}

A lathe s a machine tool which rotates the workpiece on its axis to perform various operations such as cutting, sanding, knurling, drilling, or deformation with tools that are applied to the workpiece to create an object which has symmetry about an axis of rotation. 
Lathes are used in wood turning, metalworking, metal spinning, and glass working. Lathes can be used to shape pottery, the best-known design being the potter's wheel. Most suitably equipped metalworking lathes can also be used to produce most solids of revolution, plane surfaces and screw threads or helices. Ornamental lathes can produce three-dimensional solids of incredible complexity. The material can be held in place by either one or two centers, at least one of which can be moved horizontally to accommodate varying material lengths. Other work holding methods include clamping the work about the axis of rotation using a chuck to a face plate, using clamps or dogs.

\section{SHAPER MACHINE:}

A shaper is a type of machine tool that uses linear relative motion between the workpiece and a single-point cutting tool to machine a linear tool path. Its cut is analogous to that of a lathe, except that it is linear instead of helical. (Adding axes of motion can yield helical tool paths, as also done in helical planning.) A shaper is analogous to a planer, but smaller, and with the cutter riding a ram that moves above a stationary work-piece, rather than the entire work-piece moving beneath the cutter. The ram is moved back and forth typically by a crank inside the column; hydraulically actuated shapers also exist.

A shaper is a type of machine tool that uses linear relative motion between the workpiece and a single-point cutting tool to machine a linear tool path. Its cut is analogous to that of a lathe, except that it is linear instead of helical. (Adding axes of motion can yield helical tool paths, as also done in helical planning.) A shaper is analogous to a planer, but smaller, and with the cutter riding a ram that moves above a stationary work-piece, rather than the entire work piece moving beneath the cutter. The ram is moved back and forth typically by a crank inside the column; hydraulically actuated shapers also exist.

\section{PLANNING MACHINE}

A planer is a type of metalworking machine tool that uses linear relative motion between the workpiece and a single-point cutting tool to machine a linear tool path. Its cut is analogous to that of a lathe, except that it is linear instead of helical. (Adding axes of motion can yield helical tool paths; see "Helical planing" below.) A planer is analogous to a shaper, but larger, and with the entire workpiece moving on a table beneath the cutter, instead of the cutter riding a ram that moves above a stationary workpiece. The table is moved back and forth on the bed beneath the cutting head either by mechanical means, such as a rack and pinion drive or a leadscrew, or by a hydraulic cylinder. 
A drill or drill motor is a tool fitted with a cutting tool attachment or driving tool attachment, usually a drill bit or driver bit, used for drilling holes in various materials or fastening various materials together with the use of fasteners. The attachment is gripped by a chuck at one end of the drill and rotated while pressed against the target material. The tip, and sometimes edges, of the cutting tool does the work of cutting into the target material. This may be slicing off thin shavings (twist drills or auger bits), grinding off small particles (oil drilling), crushing and removing pieces of the workpiece (SDS masonry drill), countersinking, counterboring, or other operations.

Drills are commonly used in woodworking, metalworking, construction and do-ityourself projects. Specially designed drills are also used in medicine, space missions and other applications.

\section{BORING MACHINE:}

In machining, boring is the process of enlarging a hole that has already been drilled (or cast), by means of a single-point cutting tool (or of a boring head containing several such tools), for example as in boring a cannon barrel. Boring is used to achieve greater accuracy of the diameter of a hole, and can be used to cut a tapered hole. There are various types of boring. The boring bar may be supported on both ends (which only works if the existing hole is a through hole), or it may be supported at one end. Line boring (line boring, line-boring) implies the former. Backboring (back boring, back-boring) is the process of reaching through an existing hole and then boring on the "back" side of the workpiece (relative to the machine headstock).

\section{MILLING MACHINE:}

A milling machine (also see synonyms below) is a machine tool used to machine solid materials. Milling machines are often classed in two basic forms, horizontal and vertical, which refers to the orientation of the main spindle. Both types range in size from small, bench-mounted devices to room-sized machines. Unlike a drill press, this holds the workpiece stationary as the drill moves axially to penetrate the material, milling machines also move the workpiece radially against the rotating milling cutter, which cuts on its sides as well as its tip. Workpiece and cutter movement are precisely controlled to less than 0.001 in $(0.025 \mathrm{~mm})$, usually by means of precision ground slides and lead screws or analogous technology. Milling machines may be manually operated, mechanically automated, or digitally automated via computer numerical control (CNC).

Milling machines can perform a vast number of operations, from simple (e.g., slot and keyway cutting, planing, drilling) to complex (e.g., contouring, die sinking). 
Cutting fluid is often pumped to the cutting site to cool and lubricate the cut and to wash away the resulting swarf.

\section{Grinding machine}

A grinding machine, often shortened to grinder, is a machine tool used for grinding, which is a type of machining using an abrasive wheel as the cutting tool. Each grain of abrasive on the wheel's surface cuts a small chip from the workpiece via shear deformation.

The grinding machine consists of a power driven grinding wheel spinning at the required speed (which is determined by the wheels diameter and manufacturers rating, usually by a formula) and a bed with a fixture to guide and hold the workpiece. The grinding head can be controlled to travel across a fixed work piece or the workpiece can be moved whilst the grind head stays in a fixed position. Very fine control of the grinding head or tables position is possible using a Vernier calibrated hand wheel, or using the features of numerical controls. 


\section{Experiment 8}

\section{Step Turning and Taper Turning on Lathe Machine}

\subsection{AIM}

:Step turning and taper turning on lathe machine

\section{Facing Operation}

Facing is the operation of machining the ends of a piece of work to produce a flat surface square with the axis. The operation involves feeding the tool perpendicular to the axis of rotation of the work piece. A regular turning tool may be used for facing a large work piece. The cutting edge should be set at the same height as the center of the work piece. The tool is brought into work piece from around the center for the desired depth of cut and then is fed outward, generally by hand perpendicular to the axis of rotation of the work piece.

\section{Rough Turning Operation}

Rough turning is the operation of removal of excess material from the work piece in a minimum time by applying high rate of feed and heavy depth of cut. The depth of cut for roughing operations in machining the work ranges from 2 to $5 \mathrm{~mm}$ and the rate of feed is from 0.3 to $1.5 \mathrm{~mm}$ per revolution of the work.

\section{Finish Turning Operation}

It requires high cutting speed, small feed, and a very small depth of cut to generate a smooth surface. The depth of cut ranges from 0.5 to $1 \mathrm{~mm}$ and feed from 0.1 to $0.3 \mathrm{~mm}$ per revolution of the work piece. Step Turning Is the operation of making 
different diameters of desired length. The diameters and lengths are measured by means of outside caliper and steel rule respectively.

\section{Taper Turning}

A taper may be defined as a uniform increase or decrease in diameter of a piece of work measured along its length. In a lathe, taper turning means to produce a conical surface by gradual reduction in diameter from a cylindrical work piece. The amount of taper in a work piece is usually specified by the ratio of the difference in diameters of the taper to its length. This is termed as the conicity designated by the letter $\mathrm{K}$.

$\mathrm{K}=(\mathrm{D}-\mathrm{d}) / \mathrm{L}$

Where, $\mathrm{D}=$ Large diameter of taper in $\mathrm{mm}$

$\mathrm{d}=$ small diameter of taper in $\mathrm{mm}$

$\mathrm{L}=$ length of tapered part in mm A taper may be turned by any one of the following methods:

a) Form tool method

b) Tail stock set over method

c) Swiveling the compound rest and

d) Taper turning attachment Taper turning by swiveling the compound rest: This method employs the principle of turning taper by rotating the work piece on the lathe axis and feeding the tool at an angle to the axis of rotation of the work piece. The tool mounted on the compound rest is attached to a circular base, graduated in degrees, which may be swiveled and clamped at any desired angle. Once the compound rest is set at the desired half taper angle, rotation of the compound slide screw will cause the tool to be fed at that angle and generate a corresponding taper. The setting of the compound rest is done by swiveling the rest at the half taper angle. This is calculated by the equation.

$\operatorname{Tan}=(\mathrm{D}-\mathrm{d}) / 2 \mathrm{~L}$

Where $=$ Half taper angle

\section{Knurling}

Knurling is the process of embossing a diamond shaped pattern of the surface of a work piece. The purpose of knurling is to provide an effective gripping surface on a work piece to proven it from slipping when operated by hand. Knurling is performed by a special knurling tool which consists of a set of hardened steel rollers in a holder with the teeth cut on their surface in a definite pattern. The tool is held rigidly on the tool post and the rollers are pressed against the revolving surface of work piece to squeeze the metal against the multiple cutting edges, producing depressions in a regular pattern on the surface of the work piece. 
Knurling is done at the slowest speed and oil is flowed on the tool and work piece. Knurling is done at the slowest speed and oil is flowed on the tool and work piece to dissipate heat generated during knurling. The feed varies from 1 to $2 \mathrm{~mm}$ per revolution.

\subsection{PROCEDURE}

1. The work piece and HSS single point cutting tool are securely held in the chuck and tool post respectively.

2. Operations such as facing, rough turning and finish turning are performed on a given mild steel bar one after the other in sequence up to the dimensions shown. Then the step turning is performed using parting tool.

3. Then the compound rest is swiveled by calculated half taper angle and taper is generated on the work piece. Rotation of the compound slide screw will cause the tool to be fed at the half-taper angle.

4. HSS single point cutting tool is replaced by the knurling tool and knurling operation is performed at the slowest speed of the spindle.

5. The knurling tool is replaced by the HSS single point tool again; the work piece is removed from the chuck and refixed with the unfinished part outside the chuck. This part is also rough turned, finish turned and facing is done for correct length.

6. Finally, the chamfering is done at the end of the work piece.

\subsection{PRECAUTIONS}

1. Operate the machine at optimal speeds

2. Do not take depth of cut more than $2 \mathrm{~mm}$.

3. Knurling should be done at slow speeds and apply lubricating oil while knurling

4. Care should be taken to obtain the required accuracy. 


\subsection{RESULT}

Required specimen obtained according to specified operations(plane turning, tapper turning and chamfering) with given dimensions 


\section{Experiment 9}

\section{Thread Cutting and knurling on lathe machine}

\subsection{AIM}

V-thread cutting on a lathe forming right hand and left hand metric threads as shown in fig.and under cutting operation

\subsection{MATERIAL REQUIRED}

Mild steel bar of $24 \mathrm{~mm}$ diameter and $100 \mathrm{~mm}$ length

\subsection{TOOLS AND EQUIPMENT REQUIRED}

1. H.S.S. single point cutting tool,

2. Grooving tool,

3. Threading tool thread gauge,

4. Outside caliper,

5. Chuck key,

6. Tool post key,

7. Steel rule. 


\subsection{Principle of Thread Cutting}

The principle of thread cutting is to produce a helical groove on a cylindrical or conical surface by feeding the tool longitudinally when the job is revolved between centers or by a chuck. The longitudinal feed should be equal to the pitch of the thread to be cut per revolution of the work piece. The lead screw of the lathe, through which the saddle receives its traversing motion, has a definite pitch. A definite ratio between the longitudinal feed and rotation of the head stock spindle should therefore be found out so that the relative speeds of rotation of the work and the lead screw will result in the cutting of a screw of the desired pitch.

This is affected by change gears arranged between the spindle and the lead screw or by the change gear mechanism or feed box used in a modern lathe.

\subsection{THREAD CUTTING OPERATION}

In a thread cutting operation, the first step is to remove the excess material from the work piece to make its diameter equal to the major diameter of the screw thread. Change gears of correct size are then fitted to the end of the bed between the spindle and the lead screw.

The shape or form of the thread depends on the shape of the cutting tool to be used. In a metric thread, the included angle of the cutting edge should be ground exactly 600 . the top of the tool nose should be set at the same height as the center of the work piece. A thread tool gauge is usually used against the turned surface to check the cutting tool, so that each face of the tool may be equally inclined to the center line of the work piece as shown. The speed of the spindle is reduced by one half to one fourth of the speed require for turning according to the type of the material being machined and the half nut is then engaged. The depth of cut usually varies from 0.05 to $0.2 \mathrm{~mm}$ is given by advancing the tool perpendicular to the axis of the work.

After the tool has produced a helical groove up to the desired length of the work, the tool is quickly withdrawn by the use of the cross slide, the half-nut disengaged and the tool is brought back to the starting position to give a fresh cut. Before re-engaging the half-nut it is necessary to ensure that the tool will follow the same path it has traversed in the previous cut, otherwise the job will be spoiled. Several cuts are necessary before the full depth of thread is reached arising from this comes the necessity to pick-up the thread which is accomplished by using a chasing dial or thread indicator.

\section{Chasing dial or thread indicator}

The chasing dial is a special attachment used in modern lathes for accurate picking up of the thread. This dial indicates when to close the split of half nuts. This 
is mounted on the right end of the apron. It consists of a vertical shaft with a worm gear engaged with the lead screw. The top of the spindle has a revolving dial marked with lines and numbers. The dial turns with the lead screw so long the half nut is not engaged.

If the half-nut is closed and the carriage moves along the dial stands still. As the dial turns, the graduations pass a fixed reference line. The half-nut is closed for all even threads when any line on the dial coincides with the reference line. For all odd threads, the half-nut is closed at any numbered line on the dial determined from the charts. If the pitch of the thread to be cut is an exact multiple of the pitch of the lead screw, the thread is called even thread, if otherwise the thread is odd thread.

In a chasing dial, the rule for determining the dial division is: In case of metric threads, the product of the pitch of lead screw and the no. of teeth on the worm wheel must be an exact multiple of the pitch of the threads to be cut. In case of English threads, the product of the threads per inch to be cut and the number of teeth on the worm wheel must be an exact multiple of the number of threads per inch of the lead screw. For example, if the pitch of the lead screw is $6 \mathrm{~mm}$ and the worm wheel has 15 teeth.

The product will be 90 . so any pitch which is exactly divisible by 90 , such as 1 , $1.25,2.25,3,3.75,4.5,5,6,7.5,9,10,15,30,45,90$ may be picked up when any line of the dial coincides with the reference line.

Right hand and left-hand thread: If the bolt advances into the nut when rotated in clockwise direction, the thread is called right-hand thread. When cutting a right-hand thread the carriage must move towards the head stock.

If the bolt advances into the nut when rotated in counter-clockwise direction, the thread is called left-hand, for a left hand thread the carriage moves away from the head stock and towards the tail stock. The job moves as always in the anti-clock wise direction when viewed from the tail stock end. The direction at which the carriage moves in relation to lathe head stock is controlled by means of the tumbler gears or bevel gear feed reversing mechanism.

\subsection{PROCEDURE:}

1. The work piece and HSS single point cutting tool are fixed in chuck and tool post respectively.

2. Operations such as facing, rough turning finish turning and step turning are performed on the given mild steel bar one after the other in sequence up to the dimensions shown. 
3. Single point cutting tool is replaced by a grooving tool and grooving operation is performed at half of the normal spindle speed.

4. The grooving tool is replaced by a threading tool. Right hand and left hand metric threads are cut on the work piece up to the required length at $1 / 4$ th of the normal speed of the spindle.

5. Threading tool replaced by a single point cutting tool again and finally chamfering is done at right end of the work piece at normal spindle speed.

\subsection{PRECAUTIONS}

1. Low spindle speeds should be used for accurate threads in thread cutting operation.

2. Ensure correct engage and dis-engage of half-nut.

3. Plenty of oil should be flowed on the work and tool during thread cutting.

\subsection{RESULT}

: Required specimen obtained according to specified operaions(thread cutting and under cutting) with given dimensions 


\section{Experiment 10}

\section{Drilling and Taping Operations}

\subsection{AIM}

Drilling and taping operation on drilling machine

\subsection{MATERIALS, TOOLS AND INSTRUMENTS REQUIRED}

1. Mild steel specimen

2. Coolant (oil and water mixture)

3. Lubricant oil

4. Nut and bolt.

5. Vernier calipers

6. Tools required
(a) Button pattern stock,
(b) Dies,
(c) Drill bids,
(d) Hand taps,
(e) Tap wrench.
(f) Dot punch
(g) Bench vice, 
(h) V-Block

(i) Brush,

(j) Allen Keys

\subsection{Introduction}

Drilling machine is a machine tool designed for drilling holes in metallic and non metallic materials. The cutting tool is a multi-point cutting tool, known as drill.

\subsection{RINCIPAL PARTS OF THE DRILLING MACHINE}

1. Head: Head contains the electric motor, v pulleys and v belt which transmit rotary motion to the drill spindle at a no. of speeds.

2. Spindle: spindle is made up of alloy steel. It rotates as well as moves up and down in a sleeve.

3. Drill chuck: It is held at the end of the drill spindle and in turn it holds the drill bit.

4. Adjustable table: It is supported on the column of the drilling machine and can be moved vertically and horizontally. It also carries slots for bolts clamping.

5. Base: It supports the column, which, in turn, supports the table, head etc.

6. Column: It is a vertical round or box section, which rests on the base and supports the head and the table.

\subsection{WORKING PRINCIPLE AND OPERATION OF DRILLING MACHINE}

Drilling machine is used to produce holes in the work piece the end cutting tool used for drilling holes in the work piece is called the drill. The drill is placed in the chuck and when the machine is $\mathrm{ON}$ the drill rotates. The linear motion is given to the drill towards the work piece, which is called feed. In order to remove the chips from the hole, drill is taken out from the hole so the combination of rotary and linear motion produces the hole in the work piece. 


\section{DRILLING OPERATIONS}

The following are the most common operations performed on the drilling machine:

1. Drilling: it is an operation of producing a circular hole in a work piece by forcing a drill in the work piece.

2. Boring: it is an operation of enlarging a hole that has already been drilled. Single point cutting tool is used in boring.

3. Reaming: Reaming is done with reamers. It is done to generate the hole of proper size and finish after drilling

4. Tapping: It is an operating of producing internal threads in a hole by means of a tap.

5. Counter Boring: It is an operation of enlarging the entry of a drilled hole to accommodate the bolt head etc. Counter boring tool does it.

6. Spot Facing: It is an operation done on the drilled hole to provide smooth seat for bolt head.

7. Counter Sinking: It is an operation to bevel the top of a drilled hole for making a conical seat. A counter sunk drill is used in this operation.

\subsection{SEQUENCE OF OPERATIONS}

1. Mark the center of hole and center punching

2. Fix the work piece on the table

3. Fix suitable drill onto the machine

4. Do champering of the hole with suitable tool

5. Use the sequential tapping as tap set $1,2,3$

6. Perform internal taping of drilled specimen

\subsection{PRECAUTIONS}

1. Coolant has to be sued while drilling

2. Lubricating oil has to be used to get smooth finish while tapping. 


\subsection{RESULT}

Required specimen obtained according to specified operaions(drilling and tapping operations) with given dimensions 
Experiment 11

Shaping and Planning 


\section{Experiment 12}

\section{Slotting}




\section{Experiment 13}

Milling 
Experiment 14

Cylindrical Surface Grinding 


\section{Experiment 15}

\section{Grinding of tool angles}

\subsection{AIM}

To perform V and Dovetail machining \& U-cut on the given work piece.

\subsection{MATERIALS REQUIRED}

Mild steel / Cast iron / Cast Aluminum.

\subsection{MACHINE REQUIRED}

Shaping machine

\subsection{MEASURING INSTRUMENTS}

1. Vernier calipers,

2. Vernier height gauge,

3. Dial indicator,

4. Required steel ball.

\section{CUTTING TOOLS}

1. H.S.S tool bit,

2. V tool, 
3. Plain tool,

4. Grooving tool.

\subsection{SEQUENCE OF OPERATIONS}

1. Measuring of specimen.

2. Fixing of specimen in the machine vice of the shaping machine

3. Giving the correct depth and automatic feed for the slot is to be made.

4. Check the slot with the Vernier calipers \& precision measurement by slip gauges at the end.

\subsection{THEORY}

The shaper also called shaping machine, is a reciprocating type of machine tool in which the ram moves the cutting tool backward and forward in a straight line to generate the flat surface. The flat surface may be horizontal, inclined or vertical.

\subsection{Principal Parts of a Shaper}

1. Base: It is a heavy and robust cast iron body which acts as a support for all other parts of the machine which are mounted over it.

2. Column (body): it is a box type iron body mounted upon the base. It acts as housing for the operating mechanism of the machine, electrical, cross rail and ram. On the top it is having two guide ways open which the ram reciprocates.

3. Cross-rail: it is a heavy cast iron construction, attached to the column at its front on the vertical guide ways. It carries two mechanisms, one for elevating the table and the other for cross travel of the table.

4. Table: it is made of cast iron and used for holding the work piece. T slots are provided on its top and sides for securing the work on to it. It slides along the cross rail to provide feed to the work.

5. Ram: It reciprocates on the guide ways provided above the column. It carries the tool head and mechanism for adjusting the stroke length. 
6. Tool Head: It is attached to the front portion of the ram and is used to hold the tool rigidly. It also provides the vertical and angular movement to the tool for cutting.

\subsection{Working principle and operation of a Shaper}

: In a shaper, a single point cutting tool reciprocates over the stationary work piece. The work piece is rigidly held in a vice or clamped directly on the table. The tool is held in the tool head mounted on the ram of the machine. When the ram moves forward, cutting of material takes place. So, it is called cutting stroke. When the ram moves backward, no cutting of material takes place so called idle stroke. The time taken during the return stroke is less as compared to forward stroke and this is obtained by quick return mechanism. The depth of cut is adjusted by moving the tool downward towards the work piece.

\subsection{PRECAUTIONS}

1. The shaping machine must be stopped before setting up or removing the work piece 2. All the chips should be removed from the cutter.

\subsection{RESULTS}

Required specimen obtained according to specified operations(shapping and grooving operations) with given dimensions 


\section{Lab Equipment ID Particulars}

\begin{tabular}{|c|c|c|c|c|c|c|}
\hline \multicolumn{2}{|c|}{ S.NoEquipment } & \multirow{2}{*}{$\begin{array}{l}\text { Make } \\
\text { MITUTOYO }\end{array}$} & Model & \multicolumn{2}{|c|}{$\begin{array}{l}\text { Unic cost } \\
\text { ID }\end{array}$} & $\begin{array}{l}\text { Purchaskiveihot } \\
\text { date date }\end{array}$ \\
\hline 1 & $\begin{array}{l}\text { Mechanical } \\
\text { Vernier } \\
\text { caliper }(150 \\
\text { mm) }\end{array}$ & & & 1 & $5,000.00$ & \\
\hline 2 & $\begin{array}{l}\text { Mechanical } \\
\text { Vernier } \\
\text { caliper }(200 \\
\text { mm) }\end{array}$ & MITUTOYO & & 1 & $5,950.00$ & \\
\hline 3 & $\begin{array}{l}\text { Mechanical } \\
\text { vernier } \\
\text { caliper(300 } \\
\text { mm) }\end{array}$ & MITUTOYO & & 1 & $10,500.00$ & \\
\hline 4 & 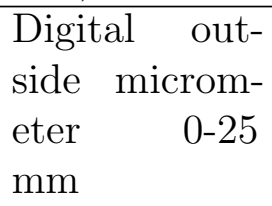 & MITUTOYO & & 1 & $3,500.00$ & \\
\hline 5 & 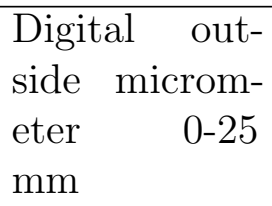 & MITUTOYO & & 1 & $5,000.00$ & \\
\hline 6 & $\begin{array}{l}\text { Jaw type In- } \\
\text { side Microme- } \\
\text { ter } 5 \text { - } 30 \mathrm{~mm} \text {, }\end{array}$ & MITUTOYO & & 1 & $7,150.00$ & \\
\hline 7 & $\begin{array}{l}\text { Jaw type In- } \\
\text { side Microme- } \\
\text { ter } 25-50 \mathrm{~mm}\end{array}$ & MITUTOYO & & 1 & $9,050.00$ & \\
\hline
\end{tabular}




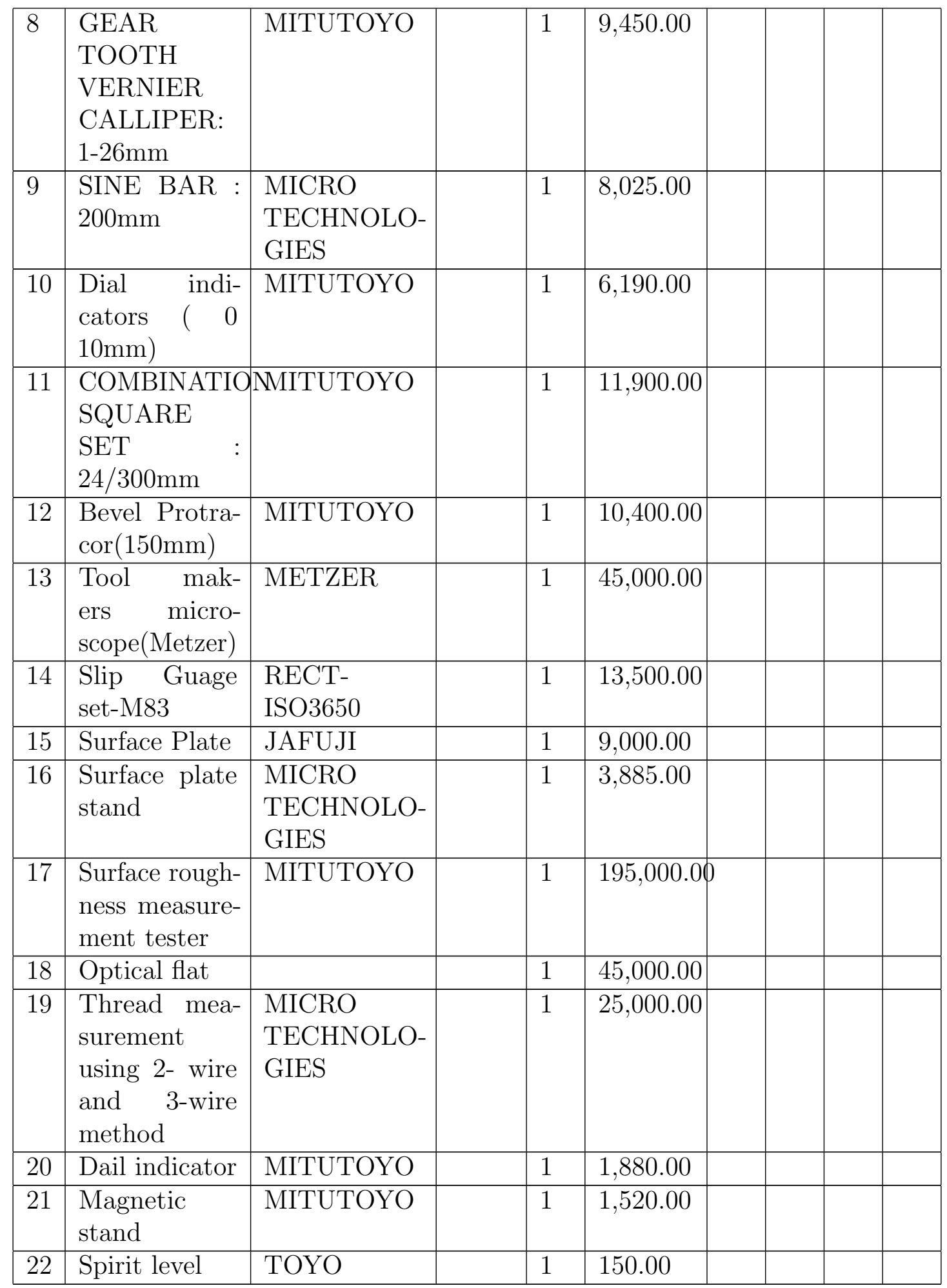




\section{References}

[1] Smith, Graham T. Machine tool metrology: An industrial handbook. Springer, 2016.

[2] Krar, Stephen F., James William Oswald, and JE St Amand. Technology of machine tools. Toronto; New York: McGraw-Hill Company of Canada, 1969.

[3]Singal, R. K., and Mridul Singal. Fundamentals of machining and machine tools. IK International Pvt Ltd, 2013.

[4] Kibbe, Richard R., John E. Neely, Roland O. Meyer, Warren T. White, Mark Bonkoski, and Paul Bradshaw. Machine tool practices. Wiley, 1982.

[5] Eren, Halit, and John G. Webster. "Measurement, Instrumentation, and Sensors Handbook: Electromagnetic, Optical, Radiation, Chemical, and Biomedical Measurement." (2014).

[6]Reddy, A. C. S., S. Rajesham, P. R. Reddy, T. P. Kumar, and J. Goverdhan. "An experimental study on effect of process parameters in deep drawing using Taguchi technique." International Journal of Engineering, Science and Technology 7, no. 1 (2015): 21-32.

[7]Reddy, A. C. S., S. Rajesham, and P. R. Reddy. "Experimental and simulation study on the warm deep drawing of AZ31 alloy." Advances in Production Engineering \& Management 10, no. 3 (2015): 153.

[8] Reddy, AC Sekhara, S. Rajesham, and P. Ravinder Reddy. "Evaluation of limiting drawing ratio (LDR) in deep drawing by rapid determination method." International Journal of Current Engineering and Technology 4, no. 2 (2014): 757-762. 